\title{
Thiol containing polymer encapsulated magnetic nanoparticles as reusable and efficiently separable adsorbent for heavy metal ions
}

\author{
Seoyoun Shin and Jyongsik Jang* \\ Received (in Cambridge, UK) 22nd May 2007, Accepted 17th July 2007 \\ First published as an Advance Article on the web 2nd August 2007 \\ DOI: 10.1039/b707706h
}

$\mathrm{Fe}_{3} \mathrm{O}_{4}$-PEDOT core-shell nanoparticles were fabricated by acid treatment mediated seeded polymerization and applied for highly efficient separation of heavy metal ions from contaminated waste water with an external magnetic field.

Heavy metal ion removal has attracted considerable attention for beneficial water usage due to their long-term environmental toxicity as well as short-term public health damage. ${ }^{1}$ To date, there have been various techniques to remove heavy metal ions such as chemical precipitation, oxidation/reduction sedimentation, ion exchange, membrane filtration and carbon adsorption. ${ }^{2}$ However, most of these processes require high capital investment and operation costs in order to maintain the separation and purification procedures for wastewater treatment. Recently, magnetic nanoparticle-polymer core-shell nanostructures have received attention in practical application fields including heavy metal ion removal from contaminated waste water. Polymer encapsulation provides the surface functionalization and protection of the magnetic core from environmental perturbation. ${ }^{3}$ Furthermore, the polymer shell also prevents the core part from particle-particle aggregation as well as improving the dispersion stability of the core-shell nanostructures in suspension medium.

Poly(3,4-ethylenedioxythiophene) (PEDOT) is one of the most promising conducting polymers because of its high conductivity, excellent environmental stability, and simple acid/base doping/ dedoping chemistry. ${ }^{4}$ In addition, PEDOT contains sulfur which can endow two unpaired electrons. This thiol-functionalized polymer is readily conjugated with positively-charged heavy metal ions according to the coordination formation. Therefore, PEDOTfunctionalized magnetic nanoparticles can be regarded as an excellent candidate for efficiently separable and reusable absorbance of heavy metal ions using an external magnetic field. ${ }^{5}$ However, there is limited information concerning a facile synthetic route to magnetic nanoparticle-PEDOT core-shell nanostructures. Thus, it is highly desirable to develop a simple and reliable method to fabricate magnetic-PEDOT core-shell nanoparticles with welldefined and uniform structure for heavy metal ion removal.

Herein we report the facile fabrication of thiol containing polymer encapsulated magnetic nanoparticles by seeded polymerization mediated with acidic etching. $\mathrm{Fe}_{3} \mathrm{O}_{4}$-PEDOT core-shell nanoparticles $\left(\mathrm{Fe}_{3} \mathrm{O}_{4}-\mathrm{PEDOT} \mathrm{NPs}\right)$ were prepared by inducing ferric cations onto the magnetic nanoparticles (MNPs) with a partial etching process followed by seeded polymerization. The

Hyperstructured Organic Materials Research Center and School of Chemical and Biological Engineering, Seoul National University,

Shinlimdong 56-1, Seoul, 151-742, Korea.

E-mail: jsjang@plaza.snu.ac.kr; Fax: 822888 1604; Tel: 8228807069 prepared $\mathrm{Fe}_{3} \mathrm{O}_{4}-\mathrm{PEDOT}$ NPs were employed as reusable and recoverable absorbents to extract heavy metal ions in aqueous solution. The adsorption capability of $\mathrm{Fe}_{3} \mathrm{O}_{4}$-PEDOT NPs was measured as a function of metal uptake time and type of heavy metal ions.

The synthetic procedure for $\mathrm{Fe}_{3} \mathrm{O}_{4}$-PEDOT NPs is illustrated in Scheme $1 . \mathrm{Fe}_{3} \mathrm{O}_{4}$ NPs were synthesized by a chemical precipitation method according to a previous report. ${ }^{6}$ Poly(vinyl alcohol) (PVA) was employed as a stabilizer of $\mathrm{Fe}_{3} \mathrm{O}_{4}$ NPs and dissolved in $1000 \mathrm{~mL}$ of distilled water ( $3 \mathrm{wt}^{\%} \%$ ). $12.43 \mathrm{~g}$ of iron(III) chloride hexahydrate $\left(\mathrm{FeCl}_{3} \cdot 6 \mathrm{H}_{2} \mathrm{O}\right)$ and $4.57 \mathrm{~g}$ of iron(II) chloride tetrahydrate $\left(\mathrm{FeCl}_{2} \cdot 4 \mathrm{H}_{2} \mathrm{O}\right)$ were added to a four-necked roundbottom reactor $(2000 \mathrm{~mL})$. The mixture was continuously stirred at $25^{\circ} \mathrm{C}$ for $30 \mathrm{~min}$ followed by the addition of aqueous ammonia solution $(1.5 \mathrm{M})$. The reaction proceeded for $2 \mathrm{~h}$ at room temperature. The $\mathrm{Fe}_{3} \mathrm{O}_{4}$ NPs were precipitated as a black sediment. The resultant MNPs were purified repeatedly by magnetic field separation with excess distilled water. The prepared $\mathrm{Fe}_{3} \mathrm{O}_{4}$ NPs were then dispersed in PVA aqueous solution $(0.5 \mathrm{M})$. Subsequently, EDOT monomer was injected into the mixed solution with vigorous stirring at $25^{\circ} \mathrm{C}$. At this step, monomer was adsorbed and covered around $\mathrm{Fe}_{3} \mathrm{O}_{4}$ NPs by hydrophobic interaction between $\mathrm{Fe}_{3} \mathrm{O}_{4} \mathrm{NPs}$ and EDOT monomer. To generate ferric cations on the $\mathrm{Fe}_{3} \mathrm{O}_{4} \mathrm{NP}$ surface, $30 \mathrm{~mL}$ of $\mathrm{HCl}(0.5 \mathrm{M})$ solution was introduced into the mixture. Then the irregular shaped $\mathrm{Fe}_{3} \mathrm{O}_{4}$ NPs were partially etched to form spherical shapes. Newly generated ferric cations were used as oxidizing agent for polymerization of EDOT monomers. ${ }^{7}$ Consequently, $\mathrm{Fe}_{3} \mathrm{O}_{4} \mathrm{NPs}$ were coated and functionalized with PEDOT. The uniform and thin PEDOT shell was produced by seeded polymerization mediated with acid treatment. The $\mathrm{Fe}_{3} \mathrm{O}_{4}$-PEDOT NPs were applied as highly efficient separable and reusable materials for heavy metal ion removal.

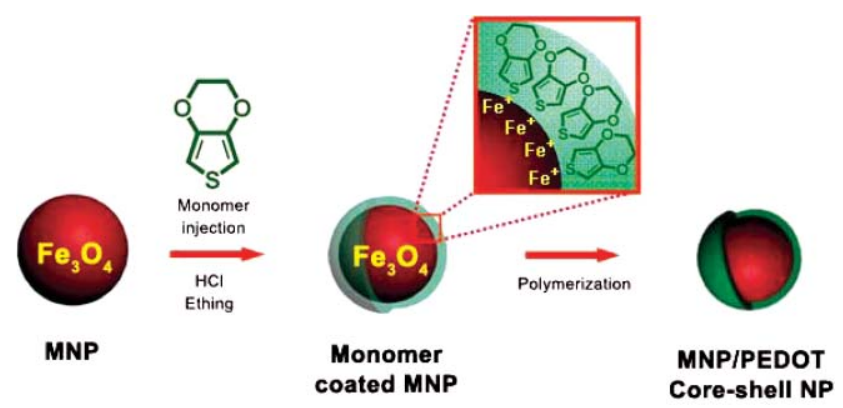

Scheme 1 The fabrication procedure of $\mathrm{Fe}_{3} \mathrm{O}_{4}$-PEDOT NPs by seeded polymerization mediated with acidic etching. 


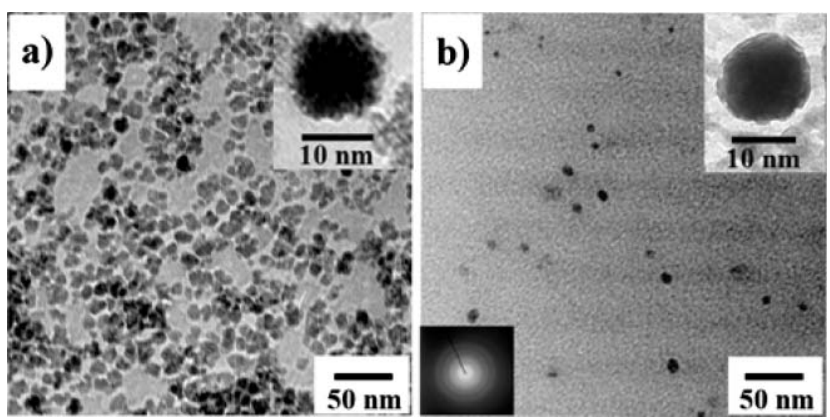

Fig. 1 TEM images of (a) $\mathrm{Fe}_{3} \mathrm{O}_{4} \mathrm{NPs}$, (b) $\mathrm{Fe}_{3} \mathrm{O}_{4}$-PEDOT NPs. Inset images (a-b) are the magnified TEM images of $\mathrm{Fe}_{3} \mathrm{O}_{4} \mathrm{NP}$ and $\mathrm{Fe}_{3} \mathrm{O}_{4}$ PEDOT NP, and the electron diffraction pattern of $\mathrm{Fe}_{3} \mathrm{O}_{4}-\mathrm{PEDOT}$ NP.

Fig. 1 shows transmission electron microscope (TEM) images of the pristine $\mathrm{Fe}_{3} \mathrm{O}_{4}$ NPs and $\mathrm{Fe}_{3} \mathrm{O}_{4}-$ PEDOT NPs. In Fig. 1(a), the pristine MNPs revealed an irregular shape and significant agglomeration after drying. The average diameter of the pristine $\mathrm{Fe}_{3} \mathrm{O}_{4}$ NPs was measured directly from TEM images and calculated as $c a .11 \mathrm{~nm}^{8}{ }^{8}$ Fig. 1(b) demonstrates the uniform and well-dispersed $\mathrm{Fe}_{3} \mathrm{O}_{4}$-PEDOT NPs. The $\mathrm{Fe}_{3} \mathrm{O}_{4}$-PEDOT NPs displayed improved stability and dispersibility in aqueous solution. This is because the PEDOT shell has a low surface energy compared to the core magnetic nanoparticles. A control experiment was performed without $\mathrm{HCl}$ addition and exhibited no coreshell formation. This means that seeded polymerization could occur at the surface of the magnetic nanoparticles with newly generated ferric cations by acidic etching. From the inset magnified image in Fig. 1(b), $\mathrm{Fe}_{3} \mathrm{O}_{4} \mathrm{NP}$ is clearly encapsulated with a PEDOT shell. $\mathrm{Fe}_{3} \mathrm{O}_{4}$-PEDOT NP has a spherical shape with a core diameter of $c a .9 \mathrm{~nm}$ and shell thickness of $c a .2 \mathrm{~nm}$. In addition, an electron diffraction pattern demonstrates that $\mathrm{Fe}_{3} \mathrm{O}_{4}$ NPs have high crystallinity and polycrystallinity. ${ }^{9}$

Fig. 2(a) represents diffuse-reflectance infrared Fourier transform (DRIFT) spectra of $\mathrm{Fe}_{3} \mathrm{O}_{4} \mathrm{NPs}, \mathrm{Fe}_{3} \mathrm{O}_{4}$-EDOT NPs and $\mathrm{Fe}_{3} \mathrm{O}_{4}-\mathrm{PEDOT}$ NPs. The DRIFT technique is an effective and powerful surface sensitive analysis. ${ }^{10}$ The characteristic peak of $\mathrm{Fe}_{3} \mathrm{O}_{4}$ NPs appeared at $587 \mathrm{~cm}^{-1}$. This band was shifted to high wavenumber compared to the $\mathrm{Fe}-\mathrm{O}$ bond peak of bulk magnetite at $570 \mathrm{~cm}^{-1}$ due to nanoparticle size. ${ }^{11}$ In order to confirm the adsorption of EDOT onto the $\mathrm{Fe}_{3} \mathrm{O}_{4}$ surface, the EDOT monomer was added to the $\mathrm{Fe}_{3} \mathrm{O}_{4} \mathrm{NP}$ solution without acid treatment, and the $\mathrm{Fe}_{3} \mathrm{O}_{4}$-EDOT NP was obtained after a washing process. The peaks at 1186 and $890 \mathrm{~cm}^{-1}$ were attributed to the $=\mathrm{C}-\mathrm{H}$ in-plane and out-of-plane deformation of EDOT monomer. These peaks disappeared after polymerization. ${ }^{12}$ The FT-IR spectrum of $\mathrm{Fe}_{3} \mathrm{O}_{4}$-PEDOT NPs showed characteristic PEDOT bands at 1384, 942 and $1083 \mathrm{~cm}^{-1}$, which are due to $\mathrm{C}=\mathrm{C}$ stretching of thiophene ring, $\mathrm{C}-\mathrm{S}$ stretching and $\mathrm{C}-\mathrm{O}$ stretching, respectively. Judging from these data, it can be concluded that the EDOT monomer on the $\mathrm{Fe}_{3} \mathrm{O}_{4}$ surface is successfully polymerized with acid treatment. In addition, the band at $1640 \mathrm{~cm}^{-1}$ is ascribed to $\mathrm{C}=\mathrm{C}$ stretching vibration, which is strongly related with the doping level of polymer. ${ }^{12}$ High intensity of this peak indicated that the PEDOT was highly doped. Fig. 2(b) exhibits the X-ray diffraction (XRD) pattern of $\mathrm{Fe}_{3} \mathrm{O}_{4}$ NPs and $\mathrm{Fe}_{3} \mathrm{O}_{4}$-PEDOT NPs. In the case of both the pristine $\mathrm{Fe}_{3} \mathrm{O}_{4}$ NPs and $\mathrm{Fe}_{3} \mathrm{O}_{4}$-PEDOT NPs, characteristic peaks of $\mathrm{Fe}_{3} \mathrm{O}_{4}$ were observed at $2 \theta=30,35$ and $43^{\circ} .{ }^{13}$ However, the XRD pattern of $\mathrm{Fe}_{3} \mathrm{O}_{4}$-PEDOT NP was broader than that of the pristine $\mathrm{Fe}_{3} \mathrm{O}_{4} \mathrm{NP}$ according to the size reduction of $\mathrm{Fe}_{3} \mathrm{O}_{4} \mathrm{NP}$ with acid treatment. ${ }^{14}$ Based on the peak at $2 \theta=35.68^{\circ}$, the mean size of $\mathrm{Fe}_{3} \mathrm{O}_{4}$ crystallites was calculated using the Scherrer equation. The value of $c a .11 \mathrm{~nm}$ of pristine $\mathrm{Fe}_{3} \mathrm{O}_{4} \mathrm{NP}$ decreased to $9 \mathrm{~nm}$ after polymerization. These values are in good agreement with the average diameters of $\mathrm{Fe}_{3} \mathrm{O}_{4} \mathrm{NPs}$ and $\mathrm{Fe}_{3} \mathrm{O}_{4}-\mathrm{PEDOT} \mathrm{NPs}$ in the TEM image. The magnetic properties of $\mathrm{Fe}_{3} \mathrm{O}_{4}$-PEDOT NPs were investigated using a SQUID magnetometer. Fig. 2(c) demonstrates the hysteresis loop of $\mathrm{Fe}_{3} \mathrm{O}_{4}-\mathrm{PEDOT}$ core-shell NPs at $300 \mathrm{~K}$. The magnetization was measured at external magnetic fields ranging between $\pm 10 \mathrm{kOe}$ and the magnetization was saturated at $24 \mathrm{emu} \mathrm{g}^{-1}$. In particular, the coercivity $\left(H_{\mathrm{C}}\right)$ from the expanded hysteresis loop between -15 and +15 Oe was found to be 7 Oe. This $H_{\mathrm{C}}$ value is considerably higher than that of bulk iron $\left(H_{\mathrm{C}} \approx 1 \mathrm{Oe}\right) .^{15}$ The inset photograph indicates that $\mathrm{Fe}_{3} \mathrm{O}_{4}-\mathrm{PEDOT}$ core-shell NPs in aqueous solution can be readily attracted and separated by an external magnetic field.

The PEDOT coated MNPs were applied as heavy metal ion absorbents. The adsorption capacities for target heavy metal ions were measured in aqueous solution to examine the surface reactivity of $\mathrm{Fe}_{3} \mathrm{O}_{4}-\mathrm{PEDOT} \mathrm{NPs} . \mathrm{Ag}^{+}, \mathrm{Hg}^{2+}$ and $\mathrm{Pb}^{2+}$ ions were selected as representative heavy metal ions. The adsorption of heavy metal ions progressed by means of surface complex formation between PEDOT shells and heavy metal ions. ${ }^{16}$ Heavy metal ion uptake of $\mathrm{Fe}_{3} \mathrm{O}_{4}$-PEDOT NPs was monitored as a function of contact time (Fig. 3(a)). Under this experimental condition, uptake saturation occurred within $2 \mathrm{~h}$, when the initial a)

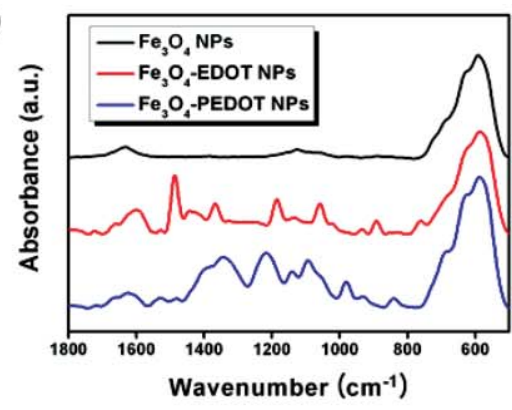

b)

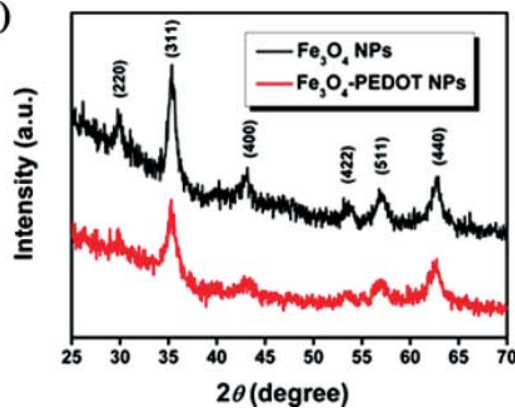

c)

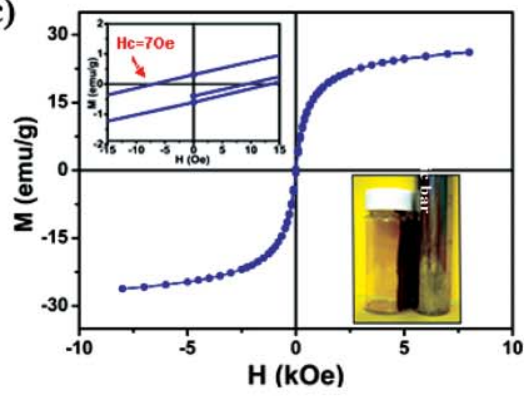

Fig. 2 (a) DRIFT spectra of $\mathrm{Fe}_{3} \mathrm{O}_{4}$ NPs, $\mathrm{Fe}_{3} \mathrm{O}_{4}$-EDOT NPs and $\mathrm{Fe}_{3} \mathrm{O}_{4}$-PEDOT NPs. (b) XRD pattern of $\mathrm{Fe}_{3} \mathrm{O}_{4}$ NPs and Fe $\mathrm{O}_{4}$-PEDOT NPs. (c) Hysteresis loop of $\mathrm{Fe}_{3} \mathrm{O}_{4} \mathrm{NPs}$ and $\mathrm{Fe}_{3} \mathrm{O}_{4}-\mathrm{PEDOT} \mathrm{NPs}$ at $300 \mathrm{~K}$ with the expanded hysteresis loop (inset). The photograph indicates that $\mathrm{Fe}_{3} \mathrm{O}_{4}-\mathrm{PEDOT}$ NPs in the aqueous solution can be attracted and arranged vertically by a magnetic bar. 

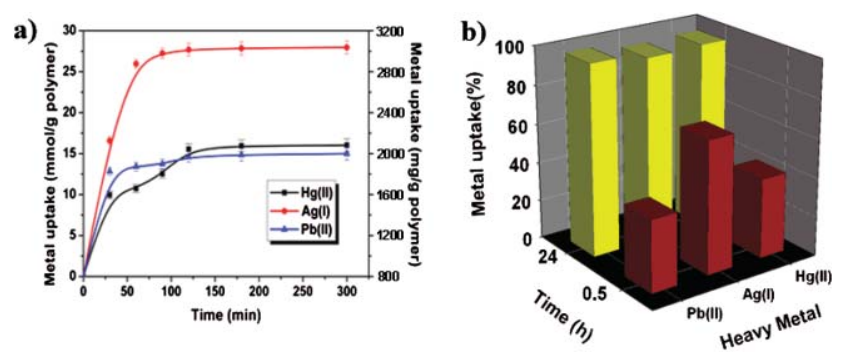

Fig. 3 Heavy metal ion uptakes of (a) $\mathrm{Fe}_{3} \mathrm{O}_{4}$-PEDOT NPs as a function of different contact times and (b) fixed contact time: 0.5 and $24 \mathrm{~h}$.

concentration of heavy metal ion was $c a .15 \mathrm{ppm}$. Based on the weight of PEDOT, the amount of $\mathrm{Ag}^{+}, \mathrm{Hg}^{2+}$ and $\mathrm{Pb}^{2+}$ ion uptake were ca. 27.96, 16.02 and $14.99 \mathrm{mmol} \mathrm{g}^{-1}$, respectively. The maximum adsorption capacity $\left(437 \mathrm{mg} \mathrm{g}^{-1}\right.$ ) of PEDOT-coated $\mathrm{Fe}_{3} \mathrm{O}_{4}$ NPs was approximately 7 times higher than that of chitosan-coated $\mathrm{Fe}_{3} \mathrm{O}_{4}$ NPs. ${ }^{17}$ In addition, this value was also high compared with that for thiol-functionalized particles (below $200 \mathrm{mg} \mathrm{g}^{-1}$ ) due to the high surface area of $\mathrm{Fe}_{3} \mathrm{O}_{4}$-PEDOT NPs and abundant unpaired electrons of PEDOT shells. ${ }^{18}$ Fig. 3(b) displays the uptake of heavy metal ions after 0.5 and $24 \mathrm{~h}$ contact time with an excess amount of $\mathrm{Fe}_{3} \mathrm{O}_{4}$-PEDOT NPs. Heavy metal ions were removed up to $95 \%$ after $24 \mathrm{~h}$, whereas the adsorption rate was observed in the order of $\mathrm{Ag}^{+}>\mathrm{Hg}^{2+}>\mathrm{Pb}^{2+}$, in accord with cation radius, and interaction enthalpy values. ${ }^{19}$ Importantly, $\mathrm{Fe}_{3} \mathrm{O}_{4}$-PEDOT NPs provide the convenient recovery of absorbents in aqueous phase by use of a magnetic field. There was no loss of adsorption capacity and morphological change of $\mathrm{Fe}_{3} \mathrm{O}_{4}-$ PEDOT NPs in recycling tests (10 repeats). TEM analysis indicated that morphological change of $\mathrm{Fe}_{3} \mathrm{O}_{4}$-PEDOT NPs does not occur after the acid treatment $\left(1 \mathrm{~h}, 25^{\circ} \mathrm{C}\right)$. In addition, the acid-treated $\mathrm{Fe}_{3} \mathrm{O}_{4}$ NPs were also attracted by the external magnetic field. Therefore, it can be concluded that the PEDOT shell strongly protects the magnetic core under acidic conditions. $\mathrm{Fe}_{3} \mathrm{O}_{4}$-PEDOT NPs could be considered as a potential candidate as an excellent reusable and recoverable adsorbent of heavy metal ions.

In conclusion, $\mathrm{Fe}_{3} \mathrm{O}_{4}-\mathrm{PEDOT} \mathrm{NPs}$ were fabricated using an acid-mediated seeded polymerization. $\mathrm{Fe}_{3} \mathrm{O}_{4} \mathrm{NPs}$ encapsulated with PEDOT were used as an efficiently separable and reusable adsorbent of heavy metal ions under an external magnetic field and had high uptake capacities for different heavy metal ions $\left(\mathrm{Ag}^{+}, \mathrm{Pb}^{2+}\right.$ and $\left.\mathrm{Hg}^{2+}\right)$. In addition, this synthetic methodology could be expanded for diverse magnetic core/polymer shell applications such as MRI contrast agents, ferrofluids, specific target drug delivery systems and data storage devices.

This work was supported by the Brain Korea 21 program of the Korea Ministry of Education

\section{Notes and references}

1 C. C. Huanga and H. T. Chang, Chem. Commun., 2007, 1215; W. C. Chang, G. S. Hsu, S. M. Chiang and M. C. Su, Bioresour.
Technol., 2006, 97, 1503; M. A. Q. Khan, S. A. Ahmed, B. Catalin, A. Khodadoust, O. Ajayi and M. Vaughn, Environ. Toxicol., 2006, 21, 513; Y. Takahashi, H. Kasai, H. Nakanishi and T. M. Suzuki, Angew. Chem., Int. Ed., 2006, 45, 913.

2 J. Jin, R. Li, H. Wang, H. Chen, K. Liang and J. Ma, Chem. Commun., 2007, 386; S. O. Hauber and M. Niemeyer, Chem. Commun., 2007, 275; G. G. Wildgoose, H. C. Leventis, A. O. Simm, J. H. Jones and R. G. Compton, Chem. Commun., 2005, 3694; G. X. S. Zhao, J. L. Lee and P. A. Chia, Langmuir, 2003, 19, 1977; S. M. C. Ritchie, K. Kissick, L. G. Bachas, S. K. Sikdar, C. Parikh and D. Bhattacharyya, Environ. Sci. Technol., 2001, 35, 3252; P. Ferruti, M. A. Marchisio and R. Duncan, Macromol. Rapid Commun., 2002, 23, 332; G. G. Wildgoose, H. C. Leventis, A. O. Simm, J. H. Jonesb and R. G. Compton, Chem. Commun., 2005, 3694.

3 S. Sun, Adv. Mater., 2006, 18, 393; D. L. Huber, Small, 2005, 1, 482; M. Kim, Y. Chen, Y. Liu and X. Peng, Adv. Mater., 2005, 17, 1429; G. Li, J. Fan, R. Jiang and Y. Gao, Chem. Mater., 2004, 16, 1835; J. Guo, W. Yang, Y. Deng, C. Wang and S. Fu, Small, 2005, 1, 737; P. Wu, J. Zhu and Z. Xu, Adv. Funct. Mater., 2004, 14, 345; F. Caruso, A. S. Susha, M. Giersig and H. Möhwald, Adv. Mater., 1999, 11, 950; P. $\mathrm{Wu}$ and $\mathrm{Z}$. Xu, Ind. Eng. Chem. Res., 2005, 44, 816; L. Zhang, W. Zhang, J. Shi, Z. Hua, Y. Li and J. Yan, Chem. Commun., 2003, 210.

4 J. Jang, $A d v$. Polym. Sci, 2006, 199, 189; J. Jang and J. H. Oh, $A d v$. Funct. Mater., 2005, 15, 494; J. Jang, J. Bae and E. Park, Adv. Mater., 2006, 18, 354; L. Groenendaal, D. F. Jonas, D. Freitag, H. Pielartzik and J. R. Reynolds, Adv. Mater., 2000, 12, 481; H. W. Heuer, R. Wehrmann and S. Kirchmeyer, Adv. Funct. Mater., 2002, 12, 89; V. Antochshuk and M. Jaroniec, Chem. Commun., 2002, 258.

5 S. Ko and J. Jang, Angew. Chem., Int. Ed., 2006, 45, 7564; T. Kang, J. Moon, S. Oh, S. Hong, S. Chahb and J. Yi, Chem. Commun., 2005, 2360; L. M. Rossi, F. P. Silva, L. L. R. Vono, P. K. Kiyohara, E. L. Duarte, R. Itri, R. Landersc and G. Machado, Green Chem., 2007, 9, 379; A. Lezzi, S. Coblanco and A. Roccero, J. Polym. Sci., Part A: Polym. Chem., 1994, 32, 1877; A. M. Liu, K. Hidajat, S. Kawi and D. Y. Zhao, Chem. Commun., 2000, 1145.

6 A. Yu. Men'shikova, B. M. Shabsel's and T. G. Evseeva, Russ. J. Appl. Chem., 2003, 76, 822.

7 A. Chen, H. Wang and X. Li, Synth. Met., 2004, 145, 153; Y. Ha, N. Nikolov, S. K. Pollack, J. Mastrangelo, B. D. Martin and R. Shashidhar, Adv. Funct. Mater., 2004, 14, 615.

8 J. Jang and K. Lee, Chem. Commun., 2002, 1098; H. G. Barth, Modern Particle Size Analysis, Wiley, New York, 1984, p. 111.

9 J. Wang, Q. Chen, C. Zeng and B. Hou, Adv. Mater., 2004, 16, 137.

10 J. Jang, Y. Nam and H. Yoon, Adv. Mater., 2005, 17, 1382.

11 G. Qiu, Q. Wang and M. Nie, Macromol. Mater. Eng., 2006, 291, 68; X. Liang, X. Wang, J. Zhuang, Y. Chen, D. Wang and Y. Li, Adv. Funct. Mater., 2006, 16, 1805.

12 J. Jang, M. Chang and H. Yoon, Adv. Mater., 2005, 17, 1616; X. Li, Y. Li, Y. Tan, C. Yang and Y. Li, J. Phys. Chem. B, 2004, 108, 5192; C. Li and T. Imae, Macromolecules, 2004, 37, 2411.

13 S. Giri, B. G. Trewyn, M. P. Stellmaker and V. S.-Y. Lin, Angew. Chem., Int. Ed., 2005, 44, 5038; J. Deng, Y. Peng, C. He, X. Long, P. Li and Albert S. C. Chan, Polym. Int., 2003, 52, 1182.

14 G. Qiu, Q. Wang and M. Nie, Macromol. Mater. Eng., 2006, 291, 68; C. R. Vestal and Z. J. Zhang, Nano Lett., 2003, 3, 1739; C. L. Lin, C. F. Lee and W. Y. Chiu, J. Colloid Interface Sci., 2005, 29, 411.

15 J. Jang and H. Yoon, Adv. Mater., 2003, 15, 2088; D. K. Kim, M. Mikhaylova, Y. Zhang and M. Muhammed, Chem. Mater., 2003, 15, 1617

16 C. A. Bell, S. V. Smith, M. R. Whittaker, A. K. Whittaker, L. R. Gahan and M. J. Monteiro, Adv. Mater., 2006, 18, 582.

17 R. Navarro, J. Guzmán, I. Saucedo, J. Revilla and E. Guibal, Macromol. Biosci., 2003, 3, 552.

18 Y. Chang and D. Chen, J. Colloid Interface Sci., 2005, 283, 446.

19 Y. Takahashi, H. Kasai, H. Nakanish and T. M. Suzuki, Angew. Chem., Int. Ed., 2006, 45, 913; P. Wu and Z. Xu, Ind. Eng. Chem. Res., 2005, 44, 816; J. Hu, I. M. C. Lo and G. Chen, Langmuir, 2005, 21, 11173. 